\title{
Infant and Young Child Feeding Pattern in Children Attending in the Outpatient Department of an Urban Hospital
}

\author{
BANANI CHAKRABORTY ${ }^{1}$, JUBAIDA RUMANA ${ }^{2}$, HOSNE ARA BEGUM $^{3}$, AFSANAAFROZ $^{4}$
}

\begin{abstract}
Background: Proper feeding practices during the first two years of life is essential for growth nutrition and development of young children. Optimum infant and young child feeding can reduce childhood mortality and morbidity significantly. Present study was done to know the infant and young child feeding pattern in the children of 0-23 months of age attending out patient department of an urban hospital.

Methods: This cross sectional study was conducted among 314 mother/child pair attending the outpatient department of an urban hospital during the period of September 2014 to December 2014.

Result: $68.5 \%$ children had early initiation of breast feeding and exclusive breast feeding among children below 6 months was $66.8 \%$. Continued breast feeding among the children of 12 to 15 months was $80.4 \%$ and $84.2 \%$ children were given solid food at 6 months of age. Adequate minimum dietary diversity, minimum meal frequency and minimal acceptable diet among children 6-23 months were $61.4 \%, 57.3 \%$ and $39.4 \%$ respectively. $64.5 \% \%$ children were taking iron rich food or supplementation.

Conclusion: Early initiation of breast feeding(0-23mo) and Exclusive breastfeeding(06 6mo) were satisfactory in the study children but IYCF practice in children of 6-23 months was not optimum and far away from the HPNSDP 2011-2016 target of 52\% of children to be fed with minimum acceptable diet.
\end{abstract}

Key words: Infant and young child feeding, Urban hospital

Introduction:

Globally childhood under nutrition is one of the most important public health challenge. Under nutrition is associated with more than one third of global disease burden of underfive children. It is estimated that $35 \%$ of all under five mortality is attributable to malnutrition. ${ }^{1}$ Over two thirds of these deaths are often associated with inappropriate feeding practices and occur during the first 2 years of life. ${ }^{2}$

Poor feeding and repeated infections resulted in 30\% of stunted under five children world wide. ${ }^{3}$ Suboptimal breastfeeding still accounts for death of 1.4 million deaths of children under five deaths and $10 \%$ of the

1. Assistant Professor, Paediatrics, BIHS General Hospital, Dhaka.

2. Registrar, Paediatrics, BIHS General Hospital.

3. Professor and Head of the Dept. Paediatrics, BIHS General Hospital .

4. Sr. Lecturer, Dept. of Bio statistics, Bangladesh University of Health Sciences.

Correspondence: Dr. Banani Chakraborty, Assistant Professor, Paediatrics. BIHS General Hospital Mirpur, Dhaka, Email.banani248@gmail.com diseases burden in children younger than 5 years. ${ }^{4}$ Failure of exclusive breast feeding at 0-5 months of age results in more than 2 fold increase risk of dying from diarrhea and pneumonia than infants who are exclusively breastfed. ${ }^{5}$ Poor complimentary feeding practice makes the children more vulnerable to stunting, poor cognitive development and increased risk of infections disease like diarrhea, acute respiratory infections ${ }^{1}$. Introduction of complementary feeding at 6 months of age can prevent $6 \%$ of under five death. It was estimated that if $90 \%$ infants are covered with a package of intervention to protect, promote and support the optimum IYCF practice almost $1 / 5$ th of overall under five mortality can be averted in developing countries. ${ }^{6}$

The first two years of life is the critical window of opportunity for the child growth Recent analysis have found that the effect of growth faltering during this period is severe on child health and survival specially for developing countries. ${ }^{7}$ Proper feeding practice during this period is essential for attaining and maintaining nutrition, growth and development of infants and young 
children. This is the age period during which the child must effectively transitioned from breast milk only to a combination of breast milk and nutritionally adequate complimentary food. Optimum infant and young children feeding practice is one of the most effective intervention to improve child health. Exclusive breast feeding upto 6 months and continuing breast feeding upto 2 years along with introduction of nutritionally adequate, safe and age appropriate complimentary feeding at 6 months are established as the top most preventive child health interventions for their effectiveness in preventing child mortality. 2,6

On this background the global strategy for infant and young child feeding was approved by World Health Assembly in may 2002 and endorsed by UNICEF. The strategy is supportive of mother and family impacting directly on early childhood survival, growth and development. These feeding practices are known collectively as IYCF practices which includes breast feeding and complementary feeding. Important aspects are early initiation of breast feeding, exclusive breast feeding for the first 6 months of life, adequate timely and appropriate complimentary feeding from 6 to 24 month of age, continued breastfeeding, adequate dietary diversity in the complimentary food and adequate frequency of meals. ${ }^{2}$

Only $38 \%$ of world infants of $0-6$ months of age are exclusively breastfed. Few children receive nutritionally adequate and safe complementary food. In many countries only a third of breastfed infants of 6-23 months meet the criteria for dietary diversity and minimum meal frequency appropriate for their age.

Inappropriate feeding practice in infant and young children is one of the most serious obstacle in maintaining nutritional status in children in Bangladesh. Rate of malnutrition is still high. BDHS data 2011 shows $41 \%$ of under five children are stunted and $36 \%$ are under weight. There has been an apparent increase in rate of exclusive breast feeding among infants under 6 months from $43 \%$ to $64 \%$ in 2011. Most of the children are weaned with rice based food which lacks protein and iron. Only $21 \%$ children of $6-23$ months of are fed minimum acceptable diet according to IYCF recommendation which is little better in urban area $(28 \%)$. Overall IYCF achievement is far away from the target of $52 \%$ of children to be fed with minimum acceptable diet by $2016 .^{8}$
Therefore studies to assess infant and young child feeding practices are relevant and important for planning improvement of child growth development and child survival. Most of the studies in our country is based on rural population. The present study is aimed to observe the pattern of infant and young child feeding in children attending at outpatient department of an urban hospital.

\section{Materials and Methods}

This is a cross sectional study conducted at the outpatient department of BIHS general hospital. During the period of September 2014 to November 2014. Sample size was calculated using standard formula among children less than 24 months. Total 330 mother child pair was interviewed. Out of them 16 were excluded due to incomplete response. 314 mother child pair were finally considered for analysis. Mother /caregiver-child pair with children 0-23 months attending the OPD were included consecutively. Children who were sick requiring emergency care or who were irritable or mothers who were unwilling to participate were excluded from study. All mothers were interviewed after obtaining informed verbal consent. Predesigned questionnaire were used for data collection. Questions regarding feeding practices were adopted from WHO questionnaires for IYCF and the indicators were considered as per guidelines. All responses were recorded by 24 hours recall method except for initiation of breast feeding and exclusive breast feeding in children 6 to 23 months of age which were elicited by historic recall.

Early intiation of breast feeding is considered when proportion of children born in last 24 months who were put on breast within one hour of birth. Exclusive breastfeeding is considered when proportion of infants 0-5 months who were fed exclusively from breast on the previous day. Minimum dietary diversity (MDD) is considered when proportion of children 6-23 months of age who received foods from at least 4 or more food groups from a total 7 groups naming (1. grains, root, tuber $/ 2$. legumes and nuts/3. diary products $/ 4$. flesh food. /5.eggs /6. vit A rich fruits, vegetables /7. other fruits and vegetables.) Minimum meal frequency (MMF) is considered when proportion of breastfed or non breastfed children of 6-23 months who receive solid semisolid or soft food the minimum number of times 
or more. For breast fed infants minimum number varies with age ( 2 times for 6-8 months and 3 times for 9-23 months) for non-breastfed children it is 4 times for 6 23 months of age. Minimum acceptable diet (MAD) is considered when proportion of children aged 6-23 months who received at the MDD and MMF according to the definitions mentioned. Data analysis was done by using SPSS software version 22 .

\section{Results}

Total 314 mother/caregiver- child pair were found eligible for analysis. Mean age of children in month was $6.85 \pm 6.15$ months. Among the study children $58.9 \%$ were below 6 months of age and $41.1 \%$ were of 6 to 23 months age group. $54.77 \%$ were male and $45.23 \%$ were female. Among the mothers $79.66 \%$ were housewives and $20.34 \%$ were students or professionals (Table-I). Mean age of mothers was 29.68 \pm 5.1 year. $42.9 \%$ mothers were diabetic. At the time of interview $59.82 \%$ mothers had single child. $92 \%$ were delivered by caesarian section.

Table-I

Socio-demographic pattern of study children

\begin{tabular}{lcc}
\hline Indicators & No & $\%$ \\
\hline Age of child & & \\
$\quad$ 0-6 months & 184 & 58.90 \\
$\quad 6-23$ months & 130 & 41.10 \\
Sex & & \\
$\quad$ Male & 172 & 54.77 \\
$\quad$ Female & 142 & 45.23 \\
Mothers education & & \\
$\quad$ Secondary incomplete & 11 & 3.5 \\
$\quad$ Secondary complete & 206 & 65.60 \\
$\quad$ Higher & 97 & 30.89 \\
Mothers occupation & & \\
$\quad$ Housewives & 250 & 79.66 \\
$\quad$ Working and students & 64 & 20.34 \\
Fathers education & & \\
$\quad$ Secondary incomplete & 0 & 0 \\
$\quad$ Secondary complete & 36 & 11.46 \\
$\quad$ Higher & 278 & 88.54 \\
\hline
\end{tabular}

Breastfeeding was initiated with in 1 hour of birth in $68.5 \%$ of the study children ( $0-23$ months). Exclusive breastfeeding was found in $66.8 \%$ children under 6 months of age (Table-II). $27.7 \%$ infants below 6 months were getting plain water, fruit juice, formula, diluted milk cows milk or solid food along with breast feeding and $6.5 \%$ were fed with formula alone (Table-III) . Exclusive breastfeeding rate was highest among 0-2 month age group (70.9\%) and after that it was declining, $65.6 \%$ in $2-4$ month and $54.3 \%$ in $4-6$ month age group (Table-IV). At the time of interview $80.4 \%$ of children of 12 to 15 months age were continuing breastfeeding (Table-II).

Table-II

IYCF status among study children

\begin{tabular}{llrc}
\hline Indicators & status & $\mathrm{N}$ & $\%$ \\
\hline Early initiation of breastfeeding & Within 1 hour & 215 & 68.4 \\
Among 0-23 months(n-314) & After 1 hour & 99 & 31.6 \\
& Total & 314 & 100 \\
Exclusive breastfeeding & Yes & 123 & 66.8 \\
among 0-6 months (n-184) & No & 61 & 33.2 \\
& Total & 184 & 100 \\
Continued breastfeeding & Yes & 45 & 80.4 \\
Among 12-15 months(n-56) & No & 11 & 19.6 \\
& Total & 56 & 100 \\
Minimum dietary diversity & Adequate & 78 & 61.4 \\
Among 6-23months (n-127) & Inadequate & 49 & 38.6 \\
& Total & 127 & 100 \\
Minimum meal frequency & Adequate & 73 & 57.3 \\
Among 6-23months (n-127) & Inadequate & 54 & 42.7 \\
& Total & 127 & 100 \\
Among 6-23 months(n-127) & No & 47 & 35.5 \\
\hline Minimum acceptable diet & Adequate & 50 & 39.4 \\
Among 6-23months(n-127) & Inadequate & 77 & 60.6 \\
& Total & 127 & 100 \\
\hline & Yes & 80 & 64.5 \\
& & 127 & 100 \\
\hline
\end{tabular}

Note: $47(58.8 \%)$ children were fed from animal source of iron

Table-III

Feeding pattern in 0-6 mo old infants(n-184)

\begin{tabular}{lcc}
\hline Pattern & Frequency & Percent \\
\hline Exclusive breastfeeding & 123 & 66.8 \\
Bf+ formula or Cows milk & 51 & 27.7 \\
Formula & 10 & 6.5 \\
\hline Total & 184 & 100 \\
\hline
\end{tabular}


Table-IV

Rate of exclusive breastfeeding according to age(06mo) $. n-184$

\begin{tabular}{lccc}
\hline Age(month) & Status & No & $\%$ \\
\hline $0-<2$ & Yes & 83 & 70.9 \\
& No & 34 & 29.1 \\
$1-<4$ & Yes & 21 & 65.6 \\
& No & 11 & 34.4 \\
$4-<6$ & Yes & 19 & 54.3 \\
& No & 16 & 45.7 \\
\hline
\end{tabular}

Complimentary feeding was introduced after completion of 6 months of age in $84.2 \%$ children . Introduction of complimentary feeding before 6 months was found in $9.6 \%$ and $6.2 \%$ children were introduced solid or semisolid food at 8 months or more (Table-V).

\section{Table-V}

Timing of introduction of complimentary food (6-23 months). $n-127$.

\begin{tabular}{lcc}
\hline Age & $\mathrm{n}-127$ & Percent \\
\hline 6 to $<$ 7months & 106 & 84.2 \\
Below 6 months & 9 & 9.6 \\
7 months or more & 12 & 6.2 \\
\hline
\end{tabular}

Minimum dietary diversity (MDD) and Minimum meal frequency (MMF) were found adequate in $61.4 \%$ and $57.3 \%$ children of $0-23$ months. Only $39.4 \%$ children were fed with Minimum acceptable diet (MAD). 64.5\% children got iron rich food or iron supplementation and $58.8 \%$ of them were fed iron from animal source (Table-II).

Early Initiation of breastfeeding was found in $41.9 \%$ infants of diabetic mothers whereas the value was $58.1 \%$ in infants of non diabetic mothers $.72 \%$ infants delivered by NVD had early initiation of breastfeeding and it was $68.2 \%$ in infants delivered by caesarian section. Exclusive breastfeeding in infant of diabetic mothers was (36.6\%) and non diabetic mother (58.3\%) (Table-VII). Rate of exclusive breastfeeding was higher $(77 \%)$ among the children of housewives than children of working mothers which is $28 \%$. Among $12-15$ months of age group who continued breast feeding $73.3 \%$ were children of housewives and $26.6 \%$ were children of working mothers (Table-VI).
Table-VI

Breastfeeding status among children of housewives and working mothers.

\begin{tabular}{lcccc}
\hline Indicators & $\begin{array}{c}\text { Housewife } \\
\mathrm{n}(\%)\end{array}$ & $\begin{array}{c}\text { Working } \\
\mathrm{n}(\%)\end{array}$ & $\begin{array}{c}\text { Total } \\
\text { Exclusive }\end{array}$ & $\begin{array}{c}{ }^{*} \mathrm{P} \\
\text { value }\end{array}$ \\
$\begin{array}{l}\text { breastfeeding } \\
0-6 \text { mo }\end{array}$ & & & & \\
$\begin{array}{l}\text { Continued } \\
\text { breastfeeding }\end{array}$ & $33(73.3)$ & $12(26.7)$ & 45(80.4) & 0.613 \\
$\begin{array}{l}\text { 12-15mo } \\
\text { *'t' test }\end{array}$ & & & & \\
\end{tabular}

Table-VII

Breastfeeding status among children of diabetic and non diabetic mothers

\begin{tabular}{llll}
\hline Indicators & $\mathrm{Dm} \mathrm{n}(\%)$ & $\mathrm{Ndm} \mathrm{n}(\%)$ & Total \\
& ${ }^{*} \mathrm{P}$ value \\
\hline
\end{tabular}

\begin{tabular}{lllll}
\hline Early initiation & $90(41.9)$ & $125(58.1)$ & $215(68.4)$ & 0.550
\end{tabular} of breastfeeding

$0-23 \mathrm{mo}$

$\begin{array}{lllll}\text { Exclusive } & 45(36.6) & 78(53.3) & 123(66.7) & 0.9\end{array}$ breastfeeding

$(0-6) 23$

$\begin{array}{lllll}\text { Continued } \quad 21(46.7) & \text { 24(53.3) } & \text { 56(80.4) } & 0.639\end{array}$ breastfeeding (12-15)

* ' $\mathrm{t}$ ' test

\section{Discussion}

Early initiation of breastfeeding within 1 hour of birth was found in $68 \%$ of study Children $(0-23 \mathrm{mo})$ which is higher than the rate ( $45 \%$ ) found in a study by Akhtar et $\mathrm{Al}^{9}$ and FSNSP report $2014(48 \%) .{ }^{10}$ It was also higher than the observations of other two similar studies $\left(31.6 \%{ }^{11}\right.$ and $\left.57 \%^{12}\right)$. A study on rural population however found that $81 \%$ mothers initiated breastfeeding with in 1 hour of birth. ${ }^{13}$

Early initiation of breastfeeding was more common in infants delivered by normal vaginal delivery $(72 \%)$ than infants delivered by caesarian section(68.2\%). It can be compared with in the rate found by Aparajita where early initiation was nil in case of caesarian section. ${ }^{11}$ It was $41.9 \%$ in diabetic mothers (most of the babies were delivered by caesarian section) and $58.1 \%$ in non diabetic mothers. The observation is not comparable with other studies. Though these observations are not statistically significant it demands attention and large scale study. 
In the present study $66.8 \%$ of $0-6$ month old children were found to be exclusively breastfed which is almost similar $(66.7 \%)$ to the observation by aparajita et al ${ }^{11}$. The result is close to BDHS 2011 data $(63.5 \%)^{8}$ and another study $(58.7 \%) .{ }^{14}$ It is better than the rate declared by FSNSP. 2014.(45\%). ${ }^{10}$

In this study rate of exclusive breastfeeding was higher among 0-2 month age group (70.9\%) and after that it is declining $65.6 \%$ in $2-4$ month and $54.3 \%$ in $4-6$ month age group. In a study of rural Bangladesh rate of exclusive breastfeeding was found $78.3 \%$ at 1 month and declined to $10.7 \%$ at 6 mo. ${ }^{15}$ The pattern is also declining in another study (74.2 at 1 month and $9 \%$ at 6 months). ${ }^{12}$

$27.7 \%$ infants below 6 months were getting plain water, fruit juice, formula other milk or complimentary food along with breast feeding and $6.5 \%$ were fed with formula alone. According to BDHS.2011, 27.2\% infants are getting plain water, fruit juice or other milk, $8.5 \%$ were getting complimentary feeding along with breastfeeding and $0.8 \%$ were not breast fed. Among the children who were not exclusively breastfed bottle feeding was quite common. In a Delhi based study prevalence of bottle feeding was $26 \%{ }^{16}$

Though statistically not significant an important observation is that the rate of exclusive breastfeeding was higher $(77 \%)$ among the children of housewives than those of working mothers were $(23 \%)$. It is observed that higher percentage $(71.3 \%)$ of mothers who had single child at the time of interview

breastfed their child exclusively for 6 months than mothers $(69.6 \%)$ who had two or more children. No association was found between mode of delivery, maternal age, maternal educational status or maternal diabetes. In a similar study exclusive breastfeeding was common among illiterate mothers and no association was found with mode of delivery ${ }^{17}$. Unlike the present study a previous study shows significant association of exclusive breastfeeding with maternal education. ${ }^{18}$

$84.2 \%$ of study children were introduced complimentary food at appropriate age (6mo completed ). Early weaning before 6 month of age was found in $9.6 \%$ and $6.2 \%$ of children were introduced solid or semisolid food after 8 months of age. In a study conducted in slum area $64 \%$ children were started with complimentary food within 6-7 months $18 \%$ were introduced weaning food after 7 months. ${ }^{9}$ It is $21 \%$ at
6 months and before 6 months and $17.6 \%$ after 7 month in another study. ${ }^{11} \mathrm{~A}$ study by Salim et al in rural Bangladesh found $24 \%$ children had weaning at appropriate time where early weaning was prominent $(50.4 \%) .{ }^{19}$

$80.4 \%$ children of $12-15$ months age group were on continued breast feeding which is lower than BDHS data (95\%) but higher than other two other studies $\left(43 \%{ }^{11}\right.$ and $\left.71.7 \%{ }^{20}\right)$.

In this study minimum dietary diversity was found to be adequate $61.4 \%$ children of $6-23$ months age group. It was $45.16 \%$ in a study conducted in Bangladesh. ${ }^{21}$ According to the observation of Aparajta et al ${ }^{11}$ and a study in Delhi ${ }^{16}$ it was $46 \%$ and $32.6 \%$ respectively but a higher rate was found in another study $(59 \%) .{ }^{22}$

$57.3 \%$ of children of $0-23$ months were fed recommended frequency of time according to age which is lower than national data $(64 \%)^{8}$ and figure obtained in other study $(78 \%)^{11}$ but better than a study in Gujrat $(48.6 \%)^{18}$ and in national health survey of india $(39 \%) .{ }^{22}$

Present study shows $39.4 \%$ children were fed with minimum acceptable diet (MAD) whereas according to national data it is $21 \% .^{8}$ It is lower than the observation by Das Aparajita which was $46 \% .{ }^{11}$ it was $51.46 \%$ according to Amanda et $\mathrm{al}^{21}$. The observation was better than two other studies $\left(19.7 \%^{16}\right.$ and $\left.29 \%^{22}\right)$.

\section{Conclusion}

Results shows that early initiation of breast feeding (0-23 mo) and Exclusive breast feeding (0-6mo) were satisfactory in the study children. But IYCF practice in 6-23 months old children was not optimum and far away from the HPNSDP 2011-2016 target of 52\% of children to be fed with minimum acceptable diet. An important observation which needs urgent attention is that frequency of exclusive breast feeding practice and continued breastfeeding was lower in working mothers than housewives. So it is recommended that steps should be taken to improve the existing situation. Awareness building programs about child care and feeding practices must be included in antenatal care, postnatal care and also during well baby visit to convey the right message about IYCF to parents and family. It is the high time to create facility for breastfeeding in work place and to take steps for uniform duration of maternity leave(6months) all over the country. 


\section{References:}

1. Black RE, Allen LH, Bahtta ZA, Claufield LE, De onis M, Ezzati M, et al. Maternal and Child Under nutrition: Global Regional Exposure and Health Consequences Lancet 2008;371:243-60.

2. World health Organization./UNICEF. Global Strategy for Infant and Young Child Feeding 2003.A55/15, Annex-16 April 2002.WHO.

3. WHO/UNICEF Global Strategy for Infant and Young Child Feeding.2003.

4. WHO Infant and Young Child Feeding : Model Chapter for Textbook for Students and Health Professionals.2009

5. Arefin S, Black RE, Antelman G, Bequi A, Claufield L, Becker S. Exclusive Breastfeeding Reduces Acute Respiratory Infection and Diarrhea Deaths Among Infants. Paediatrics. 2001;108:1-8.

6. Jones G, Streketee RW, Black RE, Bhutta ZA. Morris SS. Bellagio Child Survival Study Group. How many child death can we prevent this year? Lancet. 2003; 362:65-71.

7. Victoria CG, Deonis M, Hallal PC, Blossner M, Shrimton R, Resin N, et al. Worldwide timing of Growth faltering: Revisiting Implications for Interventions. Paediatrics. 2010; 125:473-80.

8. Bangladesh Demographic and Health Survey 2011.Preliminary Report. National Institute of Population Research and Training. Dhaka Bangladesh.

9. Akhtar K, Haque ME, Islam MZ, Sharif Al. Feeding Pattern and Nutritional Status of Under Two Years Slum Children. J Saheed Shurawardy Med Coll. 2012; 4:3-6.

10. Food Security and Nutrition Surveillance Report 2012 in collaboration with BBF,HKI. March 2012.

11. Aparajita D, Sourav N, Soumalya R, Arnab G, Ram P. Assessment of Infant and Young Child Feeding Practices Among Mothers in a Slum Area of Kolkata: A Cross Sectional study. Int J Biol Med Res. 2014;5:3855-61.

12. Ulak et al. Infant Feeding Practices in Bhaktapur Nepal.A Cross Sectional Health Facility Based Survey. International Breastfeeding Journal. 2012;7:1.
13. Modhu K, Chowdhury S, Masthi R. Breastfeeding Practices and Newborn Care in Rural Areas: A Descriptive Cross Sectional Study. Indian J Community Med. 2009; 34:243-246.

14. Das N. Infant and Young Child Feeding Perception and Practices Among Mothers in a Rural Area of West Bengal. India. Ann Med Health Sci Res. 2013; 3: 370-75.

15. Edward AF, Kuntal KS. Appropriate Infant and Young Child Feeding Result in Better Growth of Infant and Young Children in Rural Bangladesh. Am J Clin Nutr. 2008;87:1852-1859.

16. Khan AM, Agarwal P, Gupta A, Kannan AT. A Study on Infant and Young Child Feeding Practices Among Mothers Attending an Urban Health Centre in East Delhi. Indian J Public Health. 2012; 56: 301-04

17. Bagur A S, Supare M S. The Infant Feeding Practices in an Urban Slum of Nagpur india. Jounal of Clinical and Diagnostic Research. 2012; 6:1525-27.

18. Varshey A, Kumar D, Patel M, Singh U. Determinants of Breast Feeding Practices in Urban Slums, Gujrat. National J Community Medicine. 2012; 3:534-37.

19. Salim M, Mita SA, Uddin MN ,Jahan NWB,Rahman MM ,Haque MA,Begam HA . Infant and Young Child Feeding Practices Upto 2 years of Age and Their Nutritional Status. Bangladesh Medical Journal. 2012; 41:14-20

20. Sinhababu A, Mukhpaddhay DK, Panja TK, Saren AB, Mandal NK, Biswas AB. Infant and Young Child Feeding in Bankura District, West Bengal India. J Health Population Nutr. 2010; 28:294-99.

21. Amanda Z, Kate W, Purnima M. Infant and Young Child Feeding Practices and Child Undernutrition Bangladesh: Insight from Nationally Representative Data. Public Health and Nutrition. 2012; 15:1697-1704.

22. National family health survey(NFHS3).India.2005-06.West Bengal. Available from :http//www.rchiips.org/nfhs. NFHS3\%20 data/wbstate-report-printed version.pdf[last assessed on 2013.Nov.28]. 